\title{
A APLICAÇÃO DOS ROYALTIES NA EDUCAÇÃO DOS MUNICÍPIOS DA REGIÃO METROPOLITANA DO RIO DE JANEIRO
}

\author{
Fábio Araíjo de Souza \\ Janaina Specht da Silva Menezes
}

\section{Resumo}

Este artigo objetiva analisar a aplicação em educação dos recursos das compensações financeiras advindas da exploração de recursos naturais, sobretudo as do petróleo, xisto betuminoso e gás natural, realizada pelos municípios da Região Metropolitana do Estado do Rio de Janeiro (RMRJ). A partir das pesquisas bibliográfica e documental, é apresentada uma análise dos dados disponíveis nos sites dos Tribunais de Contas do Estado e do Município, bem como no da Transparência e/ou das Secretarias de Fazenda Municipais. Entre outros resultados, o trabalho revela que dos 22 municípios integrantes da RMRJ, apenas oito $(36,4 \%)$ declararam investir parte desses recursos em educação, e, destes, apenas cinco disponibilizaram a descrição das despesas pagas, fato que dificulta a investigação e análise do destino desses recursos. Revela, ainda, que a destinação à educação, disposta no ordenamento jurídico, de $75 \%$ dos recursos dos royalties, vem sendo refreada por processos de judicialização, os quais aguardam julgamento no Supremo Tribunal Federal.

Palavras-chave: financiamento da educação; royalties; participação especial; pré-sal.

\section{THE APPLICATION OF THE ROYALTIES IN EDUCATION BY THE MUNICIPALITIES OF THE METROPOLITAN REGION OF THE RIO DE JANEIRO}

\section{Abstract}

This article aims to analyze the application in education of the resources of financial compensation arising from the exploitation of natural resources, especially those of oil, oil shale and natural gas and the pre-salt carried out by the municipalities of the Metropolitan Region of the State of Rio de Janeiro (RMRJ). Based on bibliographic and documentary research, an analysis of the data available on the websites of the State and Municipal Audit Courts is presented, as well as on the Transparency and/or Municipal Finance Departments. It was revealed that of the 22 municipalities of the RMRJ, only eight (36.4\%) declared to invest part of these resources in education, and, of these, only five made available the description of the expenses paid, a fact that makes difficult the investigation and analysis of the destination of these resources. Among other results, it was exposed that the destination, for education, of $75 \%$ of the royalties resources has been restrained by judicial processes, which are awaiting judgment in the Federal Supreme Court.

Keywords: education funding; royalties; special participation, pre-salt.

\section{LA APLICACIÓN DE REGALÍAS EN LA EDUCACIÓN DE MUNICIPIOS EN LA REGIÓN METROPOLITANA DE RÍO DE JANEIRO}

Resumen

El presente artículo tiene por objeto analizar la aplicación en la educación de los recursos de la compensación financiera derivada de la explotación de los recursos naturales, especialmente los de petróleo, esquisto bituminoso y gas natural y el presal realizado por los municipios de la Región Metropolitana del Estado de 
Río de Janeiro (RMRJ). Sobre la base de la investigación bibliográfica y documental, se presenta un análisis de los datos disponibles en los sitios web de los Tribunales de Cuentas estatales y municipales, así como en los sitios web de los Departamentos de Transparencia y/o Finanzas Municipales. Se reveló que de los 22 municipios de la RMRJ, sólo ocho (36,4\%) declararon invertir parte de estos recursos en la educación, y, de éstos, sólo cinco pusieron a disposición la descripción de los gastos pagados, hecho que dificulta la investigación y el análisis del destino de estos recursos. Entre otros resultados, se expuso que el destino, para la educación, del $75 \%$ de los recursos de las regalías ha sido restringido por procesos judiciales, que están pendientes de sentencia en el Tribunal Supremo Federal.

Palabras clave: financiación de la educación; regalías; participación especial, pre-sal.

\section{IN'TRODUÇÃO}

É recorrente que a discussão acerca dos recursos públicos para a educação se concentre nas fontes obrigatórias de receita, como no percentual mínimo da receita de impostos e, adicionalmente, no salário-educação, ambos previstos no Artigo 212 da Constituição da República Federativa do Brasil (CRFB) de 1988 (BRASIL, 1988). Contudo, há várias fontes de recursos que movimentam quantias significativas para a educação, dentre elas: os serviços educacionais, os convênios, os royalties e as demais compensações financeiras advindas da exploração de recursos naturais - tais como: o petróleo e o gás natural; os hídricos, para a produção de energia elétrica; e os minerais -, além de outras receitas dos entes federados.

A discussão sobre fontes de recursos para o financiamento da educação conquistou especial destaque quando, com vistas a ir ao encontro do cumprimento de suas diferentes metas, o Plano Nacional de Educação (PNE) 2014-2024 estabeleceu que o "investimento público em educação pública" deverá atingir, no mínimo, 10\% do Produto Interno Bruto (PIB) ao final do decênio da sua vigência, determinando, como meta intermediária, o patamar de $7 \%$, ao final do quinto ano (BRASIL, 2014, Meta 20). Formulado em meio às discussões associadas à divulgação da descoberta de petróleo no pré-sal, no país, dentre as estratégias voltadas para o cumprimento da Meta 20, o PNE 2014-2024 estabeleceu que devem ser destinados à Manutenção e Desenvolvimento do Ensino (MDE), de forma adicional aos recursos vinculados à educação por meio do Artigo 212 da CRFB / 88, "[...] parcela da participação no resultado ou da compensação financeira pela exploração de petróleo e gás natural e outros recursos" (BRASIL, 2014, Estratégia 20.3).

Assim, buscando contribuir para o avanço das discussões acerca das compensações financeiras advindas da exploração de recursos naturais, sobretudo, as do petróleo, xisto betuminoso e gás natural, no contexto do financiamento da educação pública, este artigo, vinculado a uma pesquisa ${ }^{1}$ de âmbito estadual, concentra sua análise na aplicação desses recursos por parte dos governos municipais da Região Metropolitana do Estado do Rio de Janeiro (RMRJ) ${ }^{2}$, sobretudo

\footnotetext{
${ }^{1}$ Este artigo decorre de uma pesquisa de âmbito estadual, interinstitucional - vinculada à Faculdade de Educação da Universidade Federal do Rio de Janeiro (UFRJ) e ao Programa de Pós-graduação em Educação da Universidade Federal do Estado do Rio de Janeiro (Unirio) -, que objetiva analisar a aplicação, na educação, dos recursos decorrentes das compensações financeiras advindas da exploração de recursos naturais, sobretudo, do petróleo, xisto betuminoso e gás natural, nos municípios do Estado do Rio de Janeiro.

2 Dentre os 92 municípios que integram o Estado do Rio de Janeiro, 22 (23,9\%) fazem parte da RMRJ. De acordo com a Fundação CEPERJ (Centro Estadual de Estatística, Pesquisa e Formação de Servidores Públicos do Rio de Janeiro), a RMRJ é constituída pelos seguintes municípios: Belford Roxo, Cachoeiras de Macacu, Duque de Caxias, Guapimirim, Itaboraí, Itaguaí, Japeri, Magé, Maricá, Mesquita, Nilópolis, Niterói, Nova Iguaçu, Paracambi, Petrópolis, Queimados, Rio Bonito, Rio de Janeiro, São Gonçalo, São João de Meriti, Seropédica e Tanguá (RIO DE JANEIRO, 2020).
} 
por tais recursos serem significativos para a maioria dos municípios fluminenses que os vem recebendo, sendo que parte deles vem sendo aplicada na educação, por alguns desses governos.

De cunho quanti-qualitativo, este trabalho parte de um exaustivo estudo bibliográfico e documental acerca do financiamento da educação e dos marcos regulatórios da produção e distribuição dos recursos do petróleo e do gás natural no Brasil. Os documentos das prestações de contas dos municípios investigados e das Leis Orçamentárias Anuais (LOAs), de acesso público e disponibilizados nos sites dos governos, fundamentaram a análise crítica das informações. $O$ recorte temporal estabelecido corresponde ao último exercício financeiro cujos dados, na época do levantamento das informações, estavam disponíveis ao público nos sites do Tribunal de Contas do Estado do Rio de Janeiro (TCE-RJ) e do Tribunal de Contas do Município do Rio de Janeiro (TCM-RJ), e/ou nos sites da Transparência Municipal e das Secretarias Municipais de Fazenda. Além desses, outro documento analisado foi o Demonstrativo das Receitas e Despesas com Manutenção e Desenvolvimento do Ensino do Relatório Resumido de Execução Orçamentária (RREO) dos municípios.

Afora esta introdução, este artigo está dividido em outras três seções: a primeira contempla os principais mo(vi)mentos do ordenamento jurídico associados à exploração e produção de petróleo e gás natural no país, com destaque para as determinações relacionadas à educação; a segunda apresenta uma análise dos dados dos recursos dos royalties dos municípios integrantes da RMRJ; e, a última, pontua algumas considerações finais.

\section{EXPLORAÇÃO E PRODUÇÃO DO PETRÓLEO NO BRASIL: MO(VI)MENTOS JURÍDICOS}

A aprovação da política nacional do petróleo, estabelecida a partir da Lei n. 2.004/1953, sancionada pelo então presidente Getúlio Vargas, regulamentou o monopólio da União sobre pesquisa, lavra, refino e transporte de petróleo e gás natural no país (BRASIL, 1953, Art. $1^{\circ}$, Incisos I, II e III), efetivado por meio da conjunção de ações de orientação e fiscalização exercidas pelo Conselho Nacional do Petróleo (CNP) ${ }^{3}$ e pela criação da empresa Petróleo Brasileiro S.A. (Petrobras) e de suas subsidiárias, entendidas como órgãos de execução da referida política (BRASIL, 1953, Art. $2^{\circ}$, Incisos I e II). Já no ato de sua criação, foi fixado, como obrigação da Petrobrás e de suas subsidiárias, o pagamento de uma "indenização" (a lei não utilizava a palavra royalties) de 5\% sobre o valor de petróleo, xisto betuminoso e gás natural aos Estados ou Territórios Federais onde ocorria a lavra/extração desses recursos (BRASIL, 1953, Art. 274), sendo que, trimestralmente, esses entes federados deveriam distribuir $20 \%$ do valor recebido aos seus municípios, na proporção da produção de óleo (BRASIL, 1953, Art. 27, \ $3^{\circ}$ ).

Embora a criação da Petrobras tenha representado a instituição do monopólio estatal sobre a indústria de petróleo e gás natural no Brasil (SANTOS, AVELLAR, 2016), a história do petróleo,

\footnotetext{
3 Pires (2000 apud SANTOS, AVELLAR, 2020, p. 225) entende que a criação do CNP se constituiu “[...] na primeira iniciativa objetiva do Estado para regular a IP\&G [Indústria de Petróleo e Gás] no Brasil como um núcleo independente de outras atividades minerais".

${ }^{4} \mathrm{O}$ caput do texto original do Artigo 27 passou por sucessivas alterações, sendo que, em 1989, a partir do avanço da exploração do petróleo em bacias marítimas, reconfiguraram-se os critérios de distribuição do percentual devido pela Petrobras, passando a incluir estados e municípios confrontantes, onde se localizassem instalações marítimas ou terrestres de embarque ou desembarque de óleo bruto ou de gás natural. Foi também a partir da redação de 1989 que surgiu no texto dessa lei a expressão "compensação financeira”, que viria a ser amplamente discutida no contexto das reflexões sobre os royalties do petróleo.
} 
no país, vem sendo perpassada por contínuas tentativas de entregá-lo à exploração estrangeira (MARTINEZ, COLACIOS, 2016). Na prática, as forças liberais nunca desistiram de submeter a exploração do petróleo brasileiro aos centros financeiros mundiais. Sob essa perspectiva, durante o governo Fernando Henrique Cardoso, do Partido da Social Democracia Brasileira (PSDB/SP), foi promulgada a Emenda Constitucional (EC) n ${ }^{\circ}$ 9/1995, que permitiu à União estabelecer contratos não só com empresas estatais mas também com empresas privadas, nacionais ou estrangeiras, constituídas sob as leis brasileiras, para pesquisa, lavra, refino, importação, exportação e transporte de petróleo e gás natural, remetendo sua regulamentação à lei ordinária (BRASIL, 1995, Art. $\left.1^{\circ}\right)$.

Assim, com a regulamentação da EC n. 9/1995, através da Lei n. 9.478/1997 (BRASIL, 1997), conhecida como Lei do Petróleo, foi criada a Agência Nacional do Petróleo (ANP), que passou a promover rodadas de licitações com ofertas de blocos exploratórios nas diversas bacias sedimentares brasileiras. Inicialmente, as licitações eram reguladas exclusivamente por contratos de concessão $0^{5}$; posteriormente, passaram a contemplar também contratos de partilha de produção ${ }^{6}$. A Lei do Petróleo surgiu no bojo dessas mudanças na política e na economia do país, sobretudo da reforma do estado brasileiro, passando "[...] a permitir que, além da Petrobras, outras empresas constituídas sob as leis brasileiras e com sede no Brasil passassem a atuar em todos os elos da cadeia do petróleo em regime de concessão ou mediante autorização da União" (CAMPELLO, 2018, p. 9).

A Lei do Petróleo apresenta os royalties - entendidos como uma compensação financeira paga pelas empresas produtoras de petróleo e gás natural ao governo, pela exploração desses recursos em território nacional - no âmbito das participações financeiras pagas, a cada mês, pelos concessionários de exploração e produção de petróleo ou gás natural, com relação a cada campo, a partir do início de sua produção comercial (BRASIL, 1997, Art. 45/47). O produto entre o volume de produção de petróleo ou gás natural e os respectivos preços de venda (em que incide a taxa de câmbio) determina a receita bruta da produção. Sobre esse valor, no contexto dos contratos de concessão, os royalties contemplam uma alíquota de $10 \%$, que pode ser reduzida até um mínimo de $5 \%$ da produção, a depender dos riscos geológicos, das expectativas de produção e de outros fatores pertinentes, sendo que tal percentual deve constar no edital de licitação (BRASIL, 1997, Art. $\left.47, \Omega 1^{\circ}\right)$. A distribuição dos royalties entre os entes federados, por sua vez, depende de critérios estipulados em leis federais, as quais vêm sendo alteradas com o passar dos anos.

Além dos royalties, outra receita governamental à qual os entes federados podem fazer jus no contexto da exploração e produção de petróleo e gás natural diz respeito à Participação Especial, que corresponde a uma compensação extraordinária, devida pelos concessionários, em casos de “[...] grande volume de produção, ou de grande rentabilidade” (BRASIL, 1997, Art. 50). A cada trimestre, aplica-se uma alíquota efetiva sobre a receita líquida do campo de extração, que resulta no valor da Participação Especial a ser recolhida (BRASIL, 1997; LIMA, 2013).

\footnotetext{
5 Esses contratos foram criados a partir da Lei n. 9.478/1997. Nesse regime, as empresas concessionárias são as únicas responsáveis pela exploração e produção, conquistando, simultaneamente, a propriedade de todo o óleo ou gás que, por ventura, venha a ser descoberto e produzido na área concedida (CBIE, 2019). Em contraposição, essas concessionárias assumem sozinhas os riscos do contrato.

6 Criado a partir da Lei n. 12.351/2010, esse regime foi concebido para ser utilizado em áreas do pré-sal em que "[...] a empresa contratada partilha com a União o excedente em Óleo, [...], segundo critérios definidos em cada contrato, resultante da diferença entre o volume total da produção e as parcelas relativas ao custo em óleo, aos royalties devidos" (CBIE, 2019). Esse regime parte do princípio de que os riscos exploratórios são extremamente baixos, associados a grandes rentabilidades.
} 
Com a descoberta das jazidas de petróleo e gás natural em águas profundas, na área denominada de "pré-sal", tornou-se imperiosa a necessidade de adequar o marco regulatório da exploração e produção desses recursos no país, ao que se seguiu um conjunto de ordenamentos voltados para essa nova realidade. Nesse contexto, o Poder Executivo "[...] encaminhou ao Congresso Nacional uma proposta de Marco Regulatório, formado por quatro projetos de lei, os quais deram origem às Leis n. 12.276/2010, n. 12.304/2010 e à Lei n. 12.351/2010" (SILVA, 2015, p. 120).

Em meio a esse processo de constituição de um ordenamento jurídico capaz de atender as demandas que deveriam emergir com o pré-sal, destaca-se, aqui, a Lei n. 12.351/2010 (BRASIL, 2010), conhecida como Lei do Pré-Sal, que, dentre suas determinações, criou o Fundo Social (FS), dispondo, ao menos parcialmente, sobre sua estrutura e fontes de recursos. Em meio ao contexto de desigualdades regionais assentado no país e à emergência de possíveis riquezas associadas a uma fonte de renda naturalmente temporária e volátil, o FS foi criado com a finalidade de se "[...] constituir fonte de recursos para o desenvolvimento social e regional, na forma de programas e projetos nas áreas de combate à pobreza e de desenvolvimento" (BRASIL, 2010, Art. 47), com focos em educação, cultura, esporte, saúde pública, ciência e tecnologia, meio ambiente e mitigação e adaptação às mudanças climáticas. De forma mais específica, o FS visa se "[...] constituir poupança pública de longo prazo com base nas receitas auferidas pela União" "(BRASIL, 2010, Art. 48, Inciso I, grifo nosso), ao que a legislação complementa determinando que os recursos destinados aos programas e projetos a ele vinculados "[...] deverão ser os resultantes do retorno sobre o capital" (BRASIL, 2010, Art. 51). Ou seja, a estratégia definida para que os recursos do FS se mantenham crescendo, mesmo derivando de uma fonte não renovável, é a de "[...] não atingir a aplicação principal, mas apenas seus rendimentos" (BENVIDO, 2012, p. 216).

Sob essa perspectiva, estruturado sobre a formação de uma poupança de longo prazo, o Fundo Social "[...] não só deve beneficiar a geração presente ao promover o desenvolvimento através da aplicação dos seus rendimentos financeiros" (SILVA, 2015, p. 121), como também “[...] preservar essa riqueza não renovável para futuras gerações” (BENVIDO, 2012, p. 221), tornandose um fundo intergeracional, ao menos teoricamente. Há que observar, contudo, que até a data do término deste artigo, o Poder Executivo ainda não havia editado o(s) ato(s) do Executivo que determinarão a estrutura e a composição do Comitê de Gestão e do Conselho Deliberativo do Fundo. Enquanto tal pendência se mantiver, “[...] entende-se que o FS ainda não está em completa operação, muito menos, está garantida sua sustentabilidade” (SILVA, 2015, p. 125).

Visando aprimorar o marco regulatório sobre a exploração de petróleo, gás natural e outros hidrocarbonetos fluidos, ao conjunto das três leis de 2010, seguiu-se a aprovação da Lei n. 12.734/2012, que estabelece mudanças nas regras de distribuição dos royalties e da Participação Especial entre os entes federados (BRASIL, 2012). Dentre outros aspectos, essa lei prevê a constituição de um Fundo Especial ${ }^{9}$, o qual, de forma inédita, passa a beneficiar, com recursos dos royalties, os municípios, os estados e, se for o caso, o Distrito Federal, que não sejam produtores ${ }^{10}$

\footnotetext{
7 Em 2006, foi confirmada a descoberta - realizada por técnicos brasileiros da Petrobras em parceria com fornecedores, universidades e centros de pesquisa (RIO DE JANEIRO, 2019) - de gigantescas jazidas de petróleo na camada do pré-sal.

9 Os recursos do Fundo Especial devem ser destinados, dentre outras áreas, à educação, saúde, segurança, programas de erradicação da miséria e da pobreza, pesquisa, ciência e tecnologia e aos programas voltados para a mitigação e adaptação às mudanças climáticas (BRASIL, 2012).

${ }^{10}$ Denominação utilizada nos casos em que a produção ocorre em terra, rios, lagos, ilhas lacustres ou fluviais.
} 
nem confrontantes ${ }^{11}$. Especificando, essa lei determina que o Fundo Especial seja formado por $49 \%$ dos royalties decorrentes da produção na plataforma continental, no mar territorial, ou na zona econômica exclusiva (bacias marítimas), e por 50\% dos royalties oriundos da produção em terra, rios, lagos, ilhas lacustres ou fluviais (bacias terrestres), sendo que, em ambos os casos, a metade desses recursos deve ser direcionada para os municípios, os estados e, se for o caso, o DF, não produtores/não confrontantes.

Por óbvio, tal reorientação no ordenamento legal acaba por diminuir a parcela dos royalties destinada aos entes federados considerados produtores ou confrontantes. Assim, em meio às polêmicas que envolvem o tema - que, dentre outras questões complexas, trazem à cena discussões inerentes tanto aos entes produtores/confrontantes quanto àqueles que já se beneficiam de um regime diferenciado do ICMS incidente sobre o petróleo (pago no destino, e não na origem) -, a então presidente Dilma Rousseff (PT/RS) vetou os artigos que redistribuíam os recursos dos royalties a estados e municípios não produtores/não confrontantes, sendo que o Congresso Federal derrubou esses vetos, mantendo o repasse de acordo com as regras do rateio do Fundo de Participação dos Estados e do Distrito Federal (FPE) e do Fundo de Participação dos Municípios (FPM).

No início do ano de 2013, por entenderem que seriam prejudicados pela Lei n. 12.734/2012, os três governadores dos estados com maior captação de royalties do país ingressaram, cada qual, com uma Ação Direta de Inconstitucionalidade (ADI) no Supremo Tribunal Federal (STF), contra as novas regras de distribuição dos royalties e da PE dispostas na referida lei. Assim, as ADIs 4916, 4917 e 4920 foram ajuizadas pelos governadores dos estados do Espírito Santo, Renato Casagrande (PSB-ES); do Rio de Janeiro, Sérgio Cabral (PMDB-RJ); e de São Paulo, Geraldo Alckmin (PSDB-SP) (BRASIL/STF, 2013b, 2013c, 2013e). Além disso, duas outras ações foram encaminhadas: a ADI 4918, com origem na Mesa da Assembleia Legislativa do Rio de Janeiro (Alerj) (BRASIL/STF, 2013d); e a ADI 5038, ajuizada pela Associação Brasileira dos Municípios com Terminais Marítimos, Fluviais e Terrestres de Embarque e Desembarque de Petróleo e Gás Natural (ABRAMT) (BRASIL/STF, 2013f).

Em meio à complexidade que envolve a temática, a ministra relatora das ADIs no STF, Cármen Lúcia, em março de 2013, a partir de uma decisão monocrática, suspendeu, em caráter cautelar, a distribuição dos royalties, conforme definido na lei supracitada (BRASIL/STF, 2013c). Assim, até que se julguem as ADIs - que reduzem o montante dos royalties das regiões produtoras/confrontantes para dividi-los também como os demais estados e municípios do país , atualmente, o que está determinado para a distribuição dos royalties é o regime antigo de distribuição, baseado nas Leis n. 7.990/89 e n. 9.478/97 (BRASIL, 1989; 1997).

Avançando no contexto do ordenamento que se seguiu à descoberta do pré-sal, após as manifestações de junho de $2013^{12}$, que contaram com a intensa presença de temas associados à educação e à saúde, em setembro do mesmo ano, foi sancionada a Lei n. 12.858, que destina para essas duas áreas uma parcela da participação no resultado da compensação financeira pela exploração de petróleo e gás natural. Mais especificamente, a referida lei estabelece que devem ser

\footnotetext{
11 Denominação utilizada nos casos em que a produção ocorre na plataforma continental, no mar territorial ou na zona econômica exclusiva.

12 Segundo Singer (2013), embora, inicialmente, vinculados ao objetivo específico da redução do preço do transporte público, com o decorrer do tempo, os acontecimentos de junho de 2013 passaram a orbitar, simultaneamente, em torno de diferentes temas, a citar: defesa da educação e da saúde, repúdio a partidos políticos e ao(s) governo(s), combate à corrupção e defesa da reforma política, impactando, por conseguinte, as ações governamentais que se seguiram.
} 
destinadas exclusivamente à educação pública (com prioridade para a educação básica) e à saúde, respectivamente, $75 \%$ e $25 \%$ das receitas dos royalties e da Participação Especial provenientes de bacias marítimas cuja declaração de comercialidade tenha sido estabelecida a partir de dezembro de 2012, independentemente do regime contratual (concessão, partilha ou cessão onerosa) (BRASIL, 2013a). O cumprimento dessa determinação legal deságua diretamente na (re)estruturação do planejamento da destinação dos royalties e da Participação Especial por parte dos entes federados, de tal forma que estes passem a considerar as ações e políticas de educação e de saúde como focos exclusivos de tais recursos, algo que a pesquisa em curso vem revelando não estar acontecendo nos estados e municípios investigados.

A matéria é, no mínimo, controversa. Se, de um lado, por exemplo, em 2019, o então governador do estado que detém o maior volume de recursos de royalties do país, Wilson Witzel (PSC-RJ), protocolou a ADI n. 6277, justificando, dentre outros motivos, que a Lei n. 12.858/2013 fere a autonomia dos entes federativos, uma vez que determina onde aplicar os recursos dos royalties e da Participação Especial (BRASIL/STF, 2013g); por outro lado, a PEC n. 39/2019, apresentada pelo senador Marcelo Castro (MDB-PI), cuja origem política está associada a um dos territórios mais pobres da federação, prevê incluir no texto constitucional aquilo que está expresso na lei supracitada, ou seja, dentre outras medidas, a PEC busca garantir que $75 \%$ dos recursos dos royalties e da Participação Especial sejam aplicados em educação pública.

Em meio à crise financeira vivenciada pelos estados brasileiros, observa-se que a aprovação da Lei n. 12.858/2013 passou a possibilitar com que recursos dos royalties - que têm vedada sua aplicação no quadro permanente de pessoal (BRASIL, 1989, Art. $8^{\circ}$ ) - possam ser destinados ao custeio de despesas com manutenção e desenvolvimento do ensino, inclusive aquelas relativas ao pagamento de despesas de natureza remuneratória a profissionais do magistério "[...] em efetivo exercício na rede pública" (BRASIL, 2013a, Art. $5^{\circ}$ ). Além disso, especificamente em relação ao Fundo Social, a Lei n. 12.858/2013 estabelece que 50\% dos recursos recebidos por esse Fundo devem ser direcionados à educação, com vista ao cumprimento das metas do Plano Nacional de Educação (BRASIL, 2013a, Art. 2º Inciso III).

\section{OS ROYALTIES APLICADOS NA EDUCAÇÃO DOS MUNICÍPIOS DA REGIÃO METROPOLITANA FLUMINENSE}

O estado do Rio de Janeiro, maior produtor de petróleo do Brasil e terceiro maior em população, apresentou o segundo maior PIB do país em 2017, totalizando mais de R $\$ 671$ bilhões, segundo dados do Instituto Brasileiro de Geografia e Estatística (IBGE, 2020). Ainda de acordo com o IBGE, paralelamente, o Rio de Janeiro apresenta uma das maiores desigualdades de renda do país, de maneira que a renda dos mais ricos é 33 vezes maior que a dos mais pobres. Além disso, segundo dados da Pesquisa Nacional por Amostra de Domicílios Contínua (Pnad-C), os pobres representam mais de $12 \%$ da população do estado, em que $2,5 \%$ estão em situação de pobreza extrema, sendo que $83 \%$ da população vivem com menos de dois salários mínimos (IBGE, 2018).

A RMRJ ${ }^{13}$ busca enfrentar problemas urbanos complexos por meio de ações conjuntas nas mais variadas áreas do serviço público dos governos que a compõe (GROSTEIN, 2001). A proposta de cooperação intermunicipal expressa a tentativa de melhorar os indicadores sociais e,

\footnotetext{
13 Dentre os 22 municípios que integram a RMRJ, 13 (59,1\%) integram a Baixada Fluminense, são eles: Duque de Caxias, São João de Meriti, Nova Iguaçu, Nilópolis, Belford Roxo, Mesquita, Japeri, Seropédica, Itaguaí, Paracambi, Magé, Guapimirim e Queimados (RIO DE JANEIRO[Estado], 2020).
} 
portanto, a qualidade de vida da população. O crescimento populacional da RMRJ - resultante, sobretudo, do fluxo migratório em busca de melhores condições de vida - culminou em um processo de conturbação que deveria ser acompanhado por políticas sociais e econômicas conjuntas.

No que se refere à distribuição dos recursos do petróleo, é importante destacar que, atualmente, os critérios para pagamento dos royalties e da Participação Especial estão amparados pela Lei n.9.478/1997, que, regulamentada pelo Decreto n.2.705/1998, trata da distribuição da parcela de royalties acima de 5\%. Já a Lei n.7.990/1989, regulamentada pelo Decreto n.1/1991, trata da distribuição da parcela de royalties até 5\%. Assim, tendo em vista que, no estado fluminense, toda produção de hidrocarbonetos ocorre no mar, o Quadro 1 apresenta, de forma resumida, a distribuição dos royalties e da Participação Especial, conforme previsto nas normas vigentes, com destaque para a esfera municipal, haja vista constituir-se foco deste trabalho.

Quadro 1: Distribuição dos royalties e da Participação Especial decorrentes da produção de petróleo e gás natural em bacias marítimas, segundo a legislação vigente

\begin{tabular}{|c|c|c|c|}
\hline \multirow{2}{*}{$\begin{array}{l}\text { Ente } \\
\text { Federado }\end{array}$} & \multicolumn{2}{|c|}{ Parcela dos Royalties } & \multirow{2}{*}{$\begin{array}{l}\text { Participação Especial } \\
(\% \text { da receita líquida })^{14}\end{array}$} \\
\hline & $\leq 5 \%$ da produção ${ }^{15}$ & $\begin{array}{l}>5 \%(\text { até } 10 \%) \mathrm{da} \\
\text { produção }{ }^{16}\end{array}$ & \\
\hline $\begin{array}{l}\text { Estados e } \\
\text { Distrito } \\
\text { Federal }\end{array}$ & Confrontantes: $30 \%$ & Confrontantes: $22,5 \%$ & Confrontantes: $40 \%$ \\
\hline Municípios & $\begin{array}{l}\text { Confrontantes e áreas } \\
\text { geoeconômicas }{ }^{17}: 30 \% \\
\text { Com instalações de } \\
\text { embarque e desembarque: } \\
10 \%\end{array}$ & $\begin{array}{l}\text { Confrontantes: } 22,5 \% \\
\text { Com instalações de } \\
\text { embarque e desembarque: } \\
7,5 \%\end{array}$ & Confrontantes: $10 \%$ \\
\hline União & Comando da Marinha: 20\% & $\begin{array}{l}\text { Comando da Marinha: } 15 \% \\
\text { Ministério da Ciência e } \\
\text { Tecnologia: } 25 \%\end{array}$ & $\begin{array}{l}\text { Ministério de Minas e } \\
\text { Energia: } 40 \% \\
\text { Ministério do Meio } \\
\text { Ambiente: } 10 \%\end{array}$ \\
\hline $\begin{array}{l}\text { Fundo } \\
\text { Especial }\end{array}$ & $\begin{array}{l}\text { 10\% (Estados/FPE: 20\%) } \\
\text { (Municípios/FPM: 80\%) }\end{array}$ & $\begin{array}{l}\text { 7,5\% (Estados/FPE: 20\%) } \\
\text { (Municípios/FPM: 80\%) }\end{array}$ & - \\
\hline
\end{tabular}

Fonte: Lima (2013), com adequações realizadas pelos autores

Por se tratar de um estudo relacionado aos municípios, serão apresentadas, aqui, algumas considerações adicionais ao Quadro 1 sobre a distribuição dos royalties e da Participação Especial, associadas, exclusivamente, a tais entes federados. Segundo o Decreto n.1/1991, o percentual de

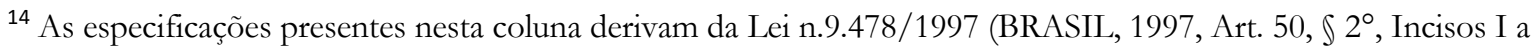
IV).

${ }^{15}$ As especificações presentes nesta coluna derivam do Decreto n.1/1991 (BRASIL, 1991, Art. 18, Incisos I a V).

${ }^{16}$ As especificações presentes nesta coluna derivam da Lei n.9.478/1997 (BRASIL, 1997, Art. 49, Inciso II, Alíneas "a" a "f").

${ }^{17}$ Identificadas a partir de critérios referentes às atividades de produção de uma dada área da produção marítima e aos efeitos dessas atividades sobre as áreas vizinhas (BRASIL, 1991, Art. 20, $₫ 1^{\circ}$ ).
} 
royalties de até $5 \%$ do valor da produção que se destina aos municípios confrontantes e suas respectivas áreas geoeconômicas - conforme o Quadro 1, equivalente a 30\% -, é dividido entre os integrantes da Zona de Produção Principal ${ }^{18}$ (ZPP) (60\%), da Zona de Produção Secundária ${ }^{19}$ (ZPS) (10\%) e da Zona Limítrofe à Zona de Produção Principal ${ }^{20}$ (ZLPP) (30\%) (BRASIL, 1991). Por sua vez, o rateio da parcela de royalties destinada aos municípios de cada zona mencionada principal, secundária e limítrofe - é determinado segundo coeficientes individuais de participação (BRASIL, 1991; RIO DE JANEIRO [Estado], 2018a).

Especificamente em relação à parcela dos royalties excedentes a 5\%, segundo a Lei n.9.478/1997, sua distribuição aos municípios dá-se na proporção das áreas de campos marítimos (sobre a plataforma continental) que se localizam entre as projeções ortogonais e paralelas de seus limites territoriais. Em casos de instalações marítimas, a lei supramencionada determina que 40\%, dos 7,5\%, sejam destinados ao município com a instalação e que os demais $60 \%$ sejam divididos, igualmente, entre os municípios da zona de influência dessa instalação (RIO DE JANEIRO [Estado], 2018a).

No que se refere à Participação Especial, os municípios fluminenses podem ser contemplados com três possibilidades distintas:

[...] (1) $10 \%$ da PE gerada por campos com declaração de comercialidade anterior a $03 / 12 / 2012$, produção realizada no Pré-sal e localizados na área definida pelo inciso IV do art. $2^{\circ}$ da Lei 12.351/10 [...]; (2) $10 \%$ da PE oriunda de campos marítimos (exceto Pré-sal), cujas declarações de comercialidade tenham ocorrido antes de 03.12.2012 [...]; e (3) 10\% da PE advinda de campos marítimos com declaração de comercialidade posterior a 03/12/2012 [...]. (RIO DE JANEIRO [Estado], 2018a, p. 34).

No que se refere à distribuição dos royalties, é importante observar que, na RMRJ, os municípios de Maricá, Rio de Janeiro, Niterói, Duque de Caxias e Itaguaí compõem a ZPP; os municípios de Cacheira de Macacu, Guapimirim e Magé integram a ZPS; e, os demais, compõem a ZLPP. Além disso, apenas os municípios de Maricá, Niterói e Rio de Janeiro receberam PE no exercício financeiro pesquisado ${ }^{21}$, correspondente ao ano de 2018 ou, excepcionalmente, de 2017.

A Tabela 1, que tem por objetivo subsidiar as discussões acerca das despesas com a educação financiadas com recursos dos royalties e da Participação Especial, demonstra que, no exercício financeiro pesquisado, apenas oito (36,4\%) munícios integrantes da RMRJ - Cachoeiras de Macacu, Guapimirim, Itaguaí, Magé, Maricá, Niterói, Petrópolis e Tanguá - aplicaram parte desses recursos na educação, sendo que em nenhum deles tal investimento ultrapassou $10 \%$ do

\footnotetext{
${ }^{18}$ Constituída pelo município confrontante e por aqueles com poços marítimos produtores, ou onde se localizam três ou mais instalações dos tipos: (a) industriais para processamento, tratamento, armazenamento e escoamento de petróleo e gás natural, excluídos os dutos; (b) ou relacionadas às atividades de apoio à exploração, produção e escoamento de petróleo e gás natural (BRASIL, 1991, Art. 20, \ 2² Inciso I, Alíneas a e b).

19 Constituída por municípios atravessados por oleodutos ou gasodutos ligados diretamente ao escoamento da produção petrolífera marítima, incluindo as respectivas estações de compressão e bombeio destinadas, exclusivamente, ao escoamento da produção (BRASIL, 1991, Art. 20, $₫ 2^{\circ}$, Inciso II).

${ }^{20} \mathrm{~A}$ ZLPP é constituída por municípios considerados contíguos àqueles da ZPP, bem como por aqueles afetados social ou economicamente pela produção ou exploração de petróleo ou gás natural (BRASIL, 1991, Art. 20, \ $2^{\circ}$, Inciso III), segundo critérios adotados pelo IBGE.

21 Os exercícios financeiros variam entre 2017 ou 2018, pois a maioria dos dados foi extraída dos documentos da prestação de contas municipais do TCE-RJ, sendo que nem todos eles tiveram suas contas de 2018 analisadas até a data do fechamento deste artigo.
} 
valor das despesas pagas. Cabe esclarecer que - na vigência das ADIs associadas à Lei n. 12.734/2012, anteriormente destacadas - não é obrigatória a aplicação em educação desses recursos advindos do petróleo, embora seja indicada, tendo em vista as dificuldades que a maioria das redes de ensino enfrenta para financiar a educação. Nesse sentido, é curioso que, em meio à situação de precariedade que, em geral, caracteriza a educação dos municípios integrantes da Baixada Fluminense, dos 13, apenas três $(23,1 \%)$ - Guapimirim, Itaguaí e Magé - apliquem recursos dos royalties na educação. Outro aspecto importante a ser destacado refere-se ao fato de que os valores das despesas pagas com recursos dos royalties podem conter também receitas de royalties minerais e hídricos, sendo que, com base nos documentos analisados - tendo em vista a ausência de uma clara distinção orçamentária -, não foi possível constatar os valores das despesas pagas com tais royalties. Cabe observar, contudo, que, no contexto do Estado Rio de Janeiro, a imensa maior parte dos royalties advém da exploração e produção do petróleo.

Tabela 1: Royalties e Participação Especial aplicados em educação, nos municípios da RMRJ 2017-2018. Valores nominais $(\mathbf{R} \$ 1,00)$

\begin{tabular}{|c|c|c|c|c|c|}
\hline $\begin{array}{l}\text { Exercício } \\
\text { Financeiro }\end{array}$ & Zona & Município & $\begin{array}{c}\text { Total de } \\
\text { despesas pagas } \\
\text { com recursos dos } \\
\text { royalties e da } \\
\operatorname{PE}^{22}(\mathrm{R} \$)\end{array}$ & $\begin{array}{c}\text { Total de } \\
\text { despesas com } \\
\text { educação pagas } \\
\text { com recursos dos } \\
\text { royalties e da } \\
\operatorname{PE}^{23}(\mathrm{R} \$) \\
\end{array}$ & $\begin{array}{l}\text { Recursos } \\
\text { aplicado } \\
\text { em } \\
\text { educação } \\
(\%)\end{array}$ \\
\hline 2018 & Principal & Maricá & $846.639 .827,58$ & $64.952 .621,64$ & 7,7 \\
\hline 2018 & Principal & Niterói & $826.285 .349,18$ & $47.045 .050,02$ & 5,7 \\
\hline 2018 & Principal & Rio de Janeiro & $495.417 .952,48$ & - & - \\
\hline 2017 & Principal & Duque de Caxias & $76.817 .279,65$ & - & - \\
\hline 2018 & Principal & Itaguaí & $41.320 .344,94$ & $3.881 .552,95$ & 9,4 \\
\hline 2018 & Secundária & Magé & $35.758 .043,13$ & $234.308,08$ & 0,7 \\
\hline 2018 & Limítrofe & São Gonçalo & $34.957 .012,81$ & - & - \\
\hline 2018 & Secundária & Guapimirim & $31.668 .474,23$ & $1.781 .853,11$ & 5,6 \\
\hline 2018 & Limítrofe & Petrópolis & $30.430 .141,37$ & $1.703 .249,20$ & 5,6 \\
\hline 2018 & Secundária & $\begin{array}{c}\text { Cachoeiras de } \\
\text { Macacu }\end{array}$ & 27.327.491,10 & $863.034,13$ & 3,2 \\
\hline 2018 & Limítrofe & Itaboraí & $17.880 .306,55$ & - & - \\
\hline 2017 & Limítrofe & Japeri & $17.880 .306,55$ & - & - \\
\hline 2018 & Limítrofe & Mesquita & $17.384 .868,02$ & - & - \\
\hline 2018 & Limítrofe & $\begin{array}{l}\text { São João de } \\
\text { Meriti }\end{array}$ & $14.821 .486,59$ & - & - \\
\hline 2018 & Limítrofe & Paracambi & $13.013 .579,18$ & - & - \\
\hline
\end{tabular}

22 Nota: No exercício observado, dentre os municípios da RMRJ, receberam PE apenas Maricá, Niterói e Rio de Janeiro.

${ }^{23}$ Nota: No exercício observado, dentre os municípios da RMRJ, receberam PE apenas Maricá, Niterói e Rio de Janeiro. 


\begin{tabular}{llcccc}
\hline $\mathbf{2 0 1 7}$ & Limítrofe & Queimados & $12.903 .664,41$ & - & - \\
$\mathbf{2 0 1 8}$ & Limítrofe & Nilópolis & $11.015 .450,52$ & - & - \\
$\mathbf{2 0 1 8}$ & Limítrofe & Belford Roxo & $9.819 .621,66$ & - & - \\
$\mathbf{2 0 1 7}$ & Limítrofe & Nova Iguaçu & $9.137 .144,03$ & - & - \\
$\mathbf{2 0 1 8}$ & Limítrofe & Tanguá & $8.546 .819,65$ & $732.480,70$ & 8,6 \\
$\mathbf{2 0 1 8}$ & Limítrofe & Seropédica & $6.250 .846,65$ & - & - \\
$\mathbf{2 0 1 7}$ & Limítrofe & Rio Bonito & $6.218 .048,78$ & - & - \\
\hline \multicolumn{7}{c}{$*$ Valores referentes às despesas pagas (TCE-RJ) } \\
\hline
\end{tabular}

Fonte: Elaborada pelos autores, com base em dados extraídos dos sites do TCE-RJ24

A Tabela 2, que apresenta o total investido em educação, bem como a parcela dessa despesa paga com royalties, concentra a atenção nos oito municípios da RMRJ que aplicaram recursos dessa fonte na educação. Dentre outros resultados, os dados nela constantes permitem a constatação de que parte significativa do total investido na educação por Maricá $(30,3 \%)$ e Niterói $(11,3 \%)$ tem como fonte os royalties advindos do petróleo. Nos demais municípios, a participação dessas receitas não ultrapassou 4\% do seu investimento total na educação, partindo de ínfimos $0,1 \%$, como é o caso do município de Magé.

Tabela 2: Participação dos royalties e Participação Especial no investimento total em educação, por município da RMRJ - 2017-2018. Valores nominais $(R \$ 1,00)$

\begin{tabular}{c|c|c|c}
\hline Município & $\begin{array}{c}\text { Total investido em } \\
\text { educação }(\mathrm{R} \$)\end{array}$ & $\begin{array}{c}\text { Total de despesas com } \\
\text { educação pagas com } \\
\text { recursos dos royalties e da } \\
\text { PE}^{25}(\mathrm{R} \$)\end{array}$ & $\begin{array}{c}\text { Participação dos royalties } \\
\text { e PE no total em } \\
\text { educação }(\%)\end{array}$ \\
\hline Cachoeiras de Macacu & $47.138 .649,00$ & $863.034,13$ & 1,8 \\
Guapimirim & $48.374 .825,38$ & $1.781 .853,11$ & 3,7 \\
Itaguaí & $171.418 .073,70$ & $3.881 .552,95$ & 2,3 \\
Magé & $196.597 .756,69$ & $234.308,08$ & 0,1 \\
Maricá & $214.384 .206,55$ & $64.952 .621,64$ & 30,3 \\
Niterói & $417.242 .801,13$ & $47.045 .050,02$ & 11,3 \\
Petrópolis & $143.621 .942,98$ & $1.703 .249,20$ & 1,2 \\
Tanguá & $28.283 .544,92$ & $732.480,70$ & 2,6 \\
\hline
\end{tabular}

Fonte: Elaborada pelos autores, a partir do site do TCE-RJ e do Sistema de Informações sobre Orçamentos

Públicos em Educação do Fundo Nacional de Desenvolvimento da Educação (SIOPE/FNDE). Os dados de

24 Nota: No exercício observado, dentre os municípios da RMRJ, receberam PE apenas Maricá, Niterói e Rio de Janeiro.

${ }^{25}$ Nota: No exercício observado, dentre os municípios da RMRJ, receberam PE apenas Maricá, Niterói e Rio de Janeiro. 
Cachoeiras de Macacu, Guapimirim e Itaguaí resultam de consulta ao Relatório Resumido e Execução

Orçamentária, já os dos demais municípios foram extraídos do Parecer Prévio nas Contas do Governo/TCE-RJ.

A Tabela 3 apresenta as despesas com educação pagas com os recursos dos royalties nos cinco governos que enviaram o detalhamento das contas da educação ao TCE-RJ. No caso de Niterói, recorreu-se aos anexos da Lei Orçamentária Anual (LOA), porém os dados referem-se à previsão das despesas. Em três governos - Cachoeiras de Macacu, Guapimirim e Itaguaí -, não foi possível encontrar no TCE-RJ nem nos anexos da LOA o detalhamento das despesas com educação referentes aos recursos dos royalties, sendo que, em dois governos - Maricá e Niterói -, tal detalhamento foi possibilitado apenas sobre parte dos recursos recebidos.

Tabela 3: Descrição da aplicação, em educação, dos recursos dos royalties e da PE, por município da RMRJ - 2017-2018. Valores nominais ( $R$ \$ 1,00)

\begin{tabular}{|c|c|c|c|c|}
\hline Município & $\begin{array}{c}\text { Total de } \\
\text { despesas com } \\
\text { educação pagas } \\
\text { com recursos } \\
\text { dos royalties e da } \\
\operatorname{PE}^{26}(\mathrm{R} \$)\end{array}$ & $\begin{array}{l}\text { Tipo de } \\
\text { despesa }\end{array}$ & Valor (R\$) & Descrição \\
\hline \multirow{2}{*}{$\begin{array}{l}\text { Cachoeiras } \\
\text { de Macacu }\end{array}$} & \multirow[t]{2}{*}{$863.034,13$} & Custeio & - & - \\
\hline & & Capital & - & - \\
\hline \multirow[t]{2}{*}{ Guapimirim } & \multirow[t]{2}{*}{$1.781 .853,11$} & Custeio & - & - \\
\hline & & Capital & - & - \\
\hline \multirow[t]{2}{*}{ Itaguaí } & \multirow[t]{2}{*}{$3.881 .552,95$} & Custeio & - & - \\
\hline & & Capital & - & - \\
\hline \multirow[t]{2}{*}{ Magé } & \multirow[t]{2}{*}{ 234.308,08 } & Custeio & $234.308,08$ & $\begin{array}{c}\text { Construção e } \\
\text { reforma/INSS/Lancee Digital } \\
\text { Produções Artísticas }\end{array}$ \\
\hline & & Capital & - & - \\
\hline \multirow[t]{2}{*}{ Maricá } & \multirow[t]{2}{*}{$64.952 .621,64$} & Custeio & $979.175,78$ & $\begin{array}{l}\text { Energia, água, telefone, reforma, } \\
\text { limpeza, vigia, locação de veículos, } \\
\text { aluguel da sede, alimentação } \\
\text { (merenda), locação de evento da } \\
\text { União Nacional dos Conselhos } \\
\text { Municipais de Educação (UNCME) }\end{array}$ \\
\hline & & Capital & $38.569,00$ & $\begin{array}{l}\text { Mobiliário, equipamento } \\
\text { informática }\end{array}$ \\
\hline \multirow[t]{2}{*}{ Niterói } & \multirow[t]{2}{*}{$47.045 .050,02$} & Custeio & $29.000 .000,00$ & $\begin{array}{l}\text { Conservação e limpeza da rede } \\
\text { escolar }\end{array}$ \\
\hline & & Capital & - & - \\
\hline
\end{tabular}

${ }^{26}$ Nota: No exercício observado, dentre os municípios da RMRJ, receberam PE apenas Maricá, Niterói e Rio de Janeiro. 
DOI: $10.12957 /$ teias. $\%$ Y.50574

\begin{tabular}{ccccc}
\hline Petrópolis & $1.703 .249,20$ & Custeio & $1.703 .249,20$ & $\begin{array}{c}\text { Ensino Superior (Universidade } \\
\text { Católica de Petrópolis - UCP) }\end{array}$ \\
Tanguá & $732.480,70$ & Capital & - & - \\
& Custeio & $732.480,70$ & $\begin{array}{c}\text { Manutenção da secretaria e } \\
\text { alimentação } \\
\end{array}$ \\
& Capital & - & - \\
\hline
\end{tabular}

Fonte: Elaborada pelos autores, a partir do site do TCE-RJ e das leis orçamentárias municipais

Especificamente em relação à descrição do investimento em educação dos recursos dos royalties, no caso de Magé, foram aplicados em construção e reforma, sendo que $\mathrm{R} \$ 22,5$ mil foram pagos à empresa Lancee Digital Produções Artísticas. Com relação às despesas de Maricá, só foi possível encontrar o detalhamento de pouco mais de $\mathrm{R} \$ 1$ milhão, o qual foi aplicado na rubrica administração e destinado ao pagamento de serviços e à compra de mobiliário e equipamento de informática. Em Niterói, a previsão de gastos com a educação, no que se refere aos recursos dos royalties, foi direcionada à conservação e limpeza da rede escolar, no valor anual de $\mathrm{R} \$ 29$ milhões. Por sua vez, o governo de Petrópolis pagou à Universidade Católica de Petrópolis (UCP) mais de $\mathrm{R}$ \$1,7 milhão, associado à aquisição de bolsas no ensino superior. É importante notar que não há ilegalidade em relação à opção de o governo investir recursos dos royalties no ensino superior. Contudo, cabe lembrar que os desafios da educação básica são muitos, e que o Plano Municipal de Educação (PME) do referido município, aprovado pela Lei n.7.334/2015, prevê o alcance de metas audaciosas associadas ao avanço da qualidade da educação básica. Por fim, ainda no que tange à Tabela 3, o município de Tanguá aplicou os recursos dos royalties na manutenção da secretaria de educação e na alimentação escolar.

Destaca-se a importância da publicização tanto dos valores quanto da descrição das despesas pagas com royalties, de tal forma que a sociedade possa ter acesso a quanto e como estão sendo aplicados esses recursos na educação. Contudo, foi possível constatar que, mesmo em documentos oficiais, é um desafio encontrar os valores e, sobretudo, a descrição das despesas com educação financiadas com recursos dos royalties. Nesse contexto, observa-se que a Lei n. 4.320/1964 determina a discriminação das receitas e despesas no orçamento (BRASIL, 1964, Art. $2^{\circ}$ ), e a Lei complementar n.101/2000, Lei de Responsabilidade Fiscal (LRF), determina o incentivo à participação popular na elaboração e discussão do orçamento (BRASIL, 2000, Art. 48, $\mathbb{S} 1^{\circ}$, Inciso I), o que significa que o orçamento deve estar acessível para a compreensão de todos, mesmo os leigos.

Mesmo o TCE-RJ, órgão que analisa tecnicamente as contas municipais, parece ter dificuldades de deter um controle preciso sobre a aplicação desses recursos. O próprio TCE-RJ reconhece que os municípios devem providenciar a "[...] criação de código de fonte específica para classificação dos recursos de royalties de que trata a Lei Federal n. 12.858/13, a fim de se apurar a destinação prevista no art. $2^{\circ}, \int 3^{\circ}$ da referida Lei" (RIO DE JANEIRO[Estado], 2018a), que trata da destinação para as áreas da educação e da saúde do equivalente a $75 \%$ e $25 \%$, das receitas resultantes dos royalties. Esses recursos do pré-sal já começaram a chegar aos municípios, mas não houve controle sobre sua classificação específica, tendo sido categorizados como royalties e aplicados em despesas alheias às previstas na lei supracitada. Tal fato denota, no mínimo, a dificuldade de os governos aplicarem os recursos públicos na educação e na saúde.

A Tabela 4 apresenta a aplicação dos recursos dos royalties em educação dos oito governos da RMRJ, por etapa/modalidade de ensino, devendo-se destacar que o município de Cachoeira de 
Macacu não encaminhou essa informação ao TCE-RJ. A partir da Tabela 4 é possível constatar que a maioria dos governos investe os recursos dos royalties nas etapas de ensino prioritárias (educação infantil e ensino fundamental), definidas no Artigo $211 \mathrm{da} C \mathrm{~F} / 88$. Apenas o governo de Petrópolis optou por entregar a uma instituição privada, a Universidade Católica de Petrópolis, através da aquisição de bolsas no ensino superior, a totalidade dos recursos recebidos por meio dos royalties. O município de Maricá incluiu as despesas de infraestrutura urbana no rol de despesas da educação, pagas com recursos dos royalties. Já os governos de Niterói e Tanguá aplicaram parte desses recursos na alimentação escolar.

Tabela 4: Aplicação, em educação, dos recursos dos royalties e da Participação Especial27, por município da RMRJ - 2017-2018. Valores nominais (R\$1,00)

\begin{tabular}{c|c|c}
\hline Município & Etapa/modalidade & Valor (R\$) \\
\hline Cachoeira de Macacu & Não especificado & 0 \\
& Educação infantil & $143.255,62$ \\
Guapimirim & Ensino fundamental & $939.085,13$ \\
& Administração geral & $699.512,36$ \\
& Educação infantil & $889.608,80$ \\
Itaguaí & Ensino fundamental & $2.980 .087,33$ \\
& Educação de jovens e adultos & $16.778,52$ \\
& Educação especial & $3.805,60$ \\
Magé & Ensino fundamental & $211.808,08$ \\
& Administração geral & $22.500,00$ \\
& Educação infantil & $11.761 .683,71$ \\
Maricá & Ensino fundamental & $44.178 .320,66$ \\
& Administração geral & $1.017 .765,78$ \\
& Infraestrutura urbana & $7.994 .851,49$ \\
& Educação infantil & $4.125 .785,63$ \\
& Ensino fundamental & $39.156 .708,36$ \\
& Administração geral & $3.612 .557,01$ \\
& Alimentação & $149.999,02$ \\
& Ensino superior & $1.703 .249,20$ \\
& Administração geral & $724.320,92$ \\
\hline \multirow{2}{*}{ Niterimentação } &
\end{tabular}

Fonte: Elaborada pelos autores, a partir do site do TCE-RJ

27 Nota: No exercício observado, dentre os municípios da RMRJ, receberam PE apenas Maricá, Niterói e Rio de Janeiro. 
O TCE-RJ observou que os municípios, ao encaminharem informações sobre as despesas com educação, utilizaram a fonte "ordinários", fato que dificultou a análise da origem dos recursos que financiaram tais despesas, com destaque para a análise da integralização do percentual mínimo vinculado à educação, disposto no Artigo 212 da Constituição Federal, de 1988. Na prática, alguns governos "inflam" o percentual mínimo vinculado à educação, incluindo, indevidamente, no seu cômputo, por exemplo, recursos associados ao salário-educação e aos royalties (RIO DE JANEIRO [Estado], 2017; 2018).

Segundo dados da ANP, o governo estadual do Rio de Janeiro recebeu R\$ 90,6 milhões, em 2018, e R \$ 95,5 milhões, em 2019, referentes à exploração do Petróleo no Campo de Mero, um dos integrantes do Bloco de Libra, situado na área de pré-sal da Bacia de Campos (RIO DE JANEIRO [Estado], 2020). Os municípios da RMRJ, por sua vez, receberam um valor total de R\$ 11,7 milhões, em 2018, e R $\$ 12$ milhões, em 2019, conforme disposto na Tabela 5, apresentada a seguir.

Tabela 5: Repasse dos royalties do Campo de Mero aos municípios da RMRJ - 2018-2019. Valores nominais $(R \$ 1,00)$

\begin{tabular}{c|cc|c|cc}
\hline \multirow{2}{*}{ Município } & \multicolumn{2}{|c|}{$\begin{array}{c}\text { Repasse dos Royalties do } \\
\text { Campo de Mero (R\$) }\end{array}$} & \multirow{2}{*}{ Município } & \multicolumn{2}{c}{$\begin{array}{c}\text { Repasse dos Royalties do } \\
\text { Campo de Mero (R\$) }\end{array}$} \\
\cline { 2 - 3 } & 2018 & 2019 & & 2018 & 2019 \\
\hline $\begin{array}{c}\text { Belford Roxo } \\
\text { Cachoeiras de } \\
\text { Macacu }\end{array}$ & $246.869,01$ & $263.411,96$ & Niterói & $1.146 .284,61$ & $1.161 .310,72$ \\
Duque de Caxias & $1.318 .259,67$ & $1.343 .119,20$ & Paracambi & $209.251,90$ & $214.315,26$ \\
Guapimirim & $619.255,53$ & $633.121,10$ & Petrópolis & $246.869,01$ & $263.411,96$ \\
Itaboraí & $387.993,14$ & $401.612,73$ & Queimados & $240.697,29$ & $256.826,67$ \\
Itaguaí & $929.773,44$ & $946.376,70$ & Rio Bonito & $197.495,21$ & $210.729,55$ \\
Japeri & $334.029,16$ & $322.829,15$ & Rio de Janeiro & $1.684 .426,97$ & $1.661 .672,22$ \\
Magé & $656.969,59$ & $681.946,73$ & São Gonçalo & $387.993,14$ & $401.612,73$ \\
Maricá & $954.902,46$ & $971.954,45$ & São João de Meriti & $246.869,01$ & $263.411,96$ \\
Mesquita & $246.869,01$ & $263.411,96$ & Seropédica & $216.010,38$ & $230.485,46$ \\
Nilópolis & $246.869,01$ & $263.411,96$ & Tanguán & $172.808,31$ & $184.388,37$ \\
\hline
\end{tabular}

Fonte: Elaborada pelos autores, a partir de dados da ANP

Da totalidade dos recursos dos royalties do Campo de Mero, que teve declarada sua comercialidade em 2017, segundo a Lei n.12.858/2013, conforme evidenciado anteriormente, 75\% deveriam ser aplicados na educação pública, com prioridade para a educação básica, e $25 \%$, em saúde. Contudo, os municípios declararam, em 2018, através de ofício ao TCE-RJ, que não receberam os recursos dos royalties referentes a esse campo petrolífero, sendo que a ANP, respondendo à consulta realizada em março de 2019, informou ao referido Tribunal que tais valores foram, sim, repassados (RIO DE JANEIRO [Estado], 2018). Assim, tendo em vista que os repasses 
dos royalties aos municípios da RMRJ, nos anos de 2018 e 2019, totalizaram aproximadamente R\$ 23,7 milhões, tal "desconhecimento" pode ter resultado na ausência de investimentos da ordem de até R \$ 17,8 milhões na manutenção e desenvolvimento do ensino desses municípios, incluindo a possível destinação para o pagamento de professores em efetivo exercício, possibilidade essa disposta no Artigo $5^{\circ}$ da lei supracitada. Sob essa perspectiva, pode causar estranheza o fato de que alguns municípios, inclusive da RMRJ, venham atrasando, parcelando, ou, até mesmo, não pagando seus servidores, incluindo os professores. Observa-se, contudo, que o levantamento e análise dos motivos para tais problemas levam à realização de estudos e pesquisas que transcendem os limites deste artigo.

Por fim, resgata-se aqui a ADI n. 6277, interposta, em 2019, pelo governador do Rio de Janeiro, que suspende os efeitos da Lei n. 12.858/2013, impondo, até que seja apreciada por parte do STF, uma situação de possível expectativa às determinações associadas ao financiamento da educação, por meio dos royalties e demais compensações vinculadas ao pré-sal.

\section{CONSIDERAÇÕES FINAIS}

Na primeira metade da década de 2010, a aprovação do ordenamento jurídico associado às descobertas de petróleo no pré-sal conjugou-se ao período de discussão, tramitação e aprovação de um novo PNE para o país. Tal conjugação, ocorrida em um país caracterizado por elevados índices de desigualdade social e por históricas dívidas educacionais, contribuiu para que o ordenamento jurídico vinculado à exploração e produção de petróleo buscasse ir de encontro a tais desafios e, sob essa perspectiva, passasse a destinar à educação parte dos recursos decorrentes dessas atividades no país.

Nesse contexto, a citar, a Lei n. 12.734/2012 estabeleceu mudanças nas regras de distribuição dos royalties e da Participação Especial entre os entes federados, passando a contemplar com tais recursos, a partir da constituição de um Fundo Especial, todos os estados e municípios do país, e não só os produtores ou confrontantes. Já a Lei n. 12.858/2013, vinculada especificamente às descobertas no pré-sal, passou a determinar que $25 \%$ e $75 \%$ das receitas dos royalties e da Participação Especial, decorrentes de poços com declaração de comercialidade estabelecida a partir de dezembro de 2012, fossem destinados exclusivamente à saúde e à educação pública, respectivamente, com prioridade para a Educação Básica, podendo esse recurso financiar, inclusive, o pagamento de despesas de natureza remuneratória a profissionais do magistério.

Contudo, ambas as legislações se encontram em suspenso, aguardando, há anos, pelo julgamento das ADIs, por parte do STF. Até que tais ações sejam apreciadas, continuam valendo as leis anteriores, as quais, em certa medida, deixam a cargo dos governos o julgamento pelo investimento (ou não!) de tais recursos na educação e/ou na saúde. Soma-se a essa questão o fato de a educação nacional, na contramão ao necessário avanço do seu investimento, já vir contando com restrições adicionais decorrentes da aprovação da EC n. 95/2016, a qual, por vinte exercícios financeiros consecutivos, não permitirá que o investimento na educação se sobreponha ao do exercício anterior, corrigido apenas pela inflação (BRASIL, 2016).

Especificamente no que tange ao investimento dos royalties e da Participação Especial por parte dos 22 municípios integrantes da RMRJ, dentre outros resultados, os dados revelaram que apenas oito $(36,4 \%)$ investem parte desses recursos na educação, possibilitando inferir que esse direito social não se constitui prioridade na destinação das receitas resultantes da exploração e produção do petróleo, ao menos por parte da maioria dos municípios pesquisados. Além disso, 
DOI: $10.12957 /$ teias. $\%$ Y.50574

dentre os municípios que declaram investir parte de tais recursos na educação, apenas cinco enviaram ao TCE-RJ a descrição das despesas com educação financiadas com recursos dos royalties.

Observou-se, também, que não é incomum que os governos apliquem os recursos dos royalties em despesas alheias às suas incumbências prioritárias - por exemplo, há municípios que aplicam esses recursos na aquisição de bolsas de estudo no ensino superior -, abrangendo, assim, níveis de ensino que consideram estratégicos politicamente. $\mathrm{O}$ uso das receitas dos royalties para pagamento de serviços de terceiros na educação é recorrente, haja vista a proibição de aplicação das receitas em gastos com pessoal permanente e em favor da dívida do ente federado, conforme determina a Lei Federal n.9.478/1997. Além disso, nos contratos de serviço, é mais difícil identificar o destino da aplicação desses recursos, indo ao encontro do crônico fisiologismo e do patrimonialismo, ensejados na relação entre governos e setor privado.

O controle e acompanhamento social da aplicação dos recursos dos royalties e da Participação Especial, sobretudo regidos pela Lei 12.858/2013, são dificultados pela falta de acesso às informações de repasses desses recursos e de transparência na sua aplicação. Para tanto os repasses deveriam ocorrer em contas bancárias separadas, pois a aplicação desses recursos é distinta, de acordo com a data dos contratos (assinados antes ou após 03/12/2012), sendo aplicados em educação, para contratos anteriores à 03/12/2012, e em Manutenção e Desenvolvimento do Ensino, para contratos posteriores a essa data.

\section{REFERENNCIAS}

BENVIDO, Juliano Zaiden. Fundo Social do pré-sal: entre a promessa e o desafio da inclusão do outro. Pensar, Fortaleza, v. 17, n. 1, p. 210-228, jan./jun. 2012.

BRASIL. [Constituição (1988)]. Constituição da República Federativa do Brasil. Brasília, DF: Presidência da República, 5 de outubro de 1988. Disponível em http://www.planalto.gov.br/ccivil_03/constituicao/constituicao.htm. Acesso em 18 jan. 2020.

BRASIL. Emenda Constitucional n. 9, de 9 de novembro de 1995. Dá nova redação ao art. 177 da Constituição Federal, alterando e inserindo parágrafos. Brasília, DF: Presidência da República, $1995 . \quad$ Disponível em http://www.planalto.gov.br/ccivil 03/constituicao/Emendas/Emc/emc09.htm. Acesso em 18 jan. 2020.

BRASIL. Emenda Constitucional n. 95, de 15 de dezembro de 2016. Altera o Ato das Disposições Constitucionais Transitórias, para instituir o Novo Regime Fiscal, e dá outras providências. Brasília, DF: Presidência da República, 2016. Disponível em http://www.planalto.gov.br/ccivil 03/Constituicao/Emendas/Emc/emc95.htm. Acesso em 2 out. 2019.

BRASIL. Senado Federal. Proposta de Emenda Constitucional n. 39, 02 de abril de 2019. Altera o art. 20 da Constituição Federal e o art. 107 do Ato das Disposições Constitucionais Transitórias para vincular as rendas do petróleo à educação e saúde e excluir essas despesas do teto de gastos instituído pelo Novo Regime Fiscal. Brasília, DF: Senado Federal, 2019. Disponível em https://www25.senado.leg.br/web/atividade/materias/-/materia/136115. Acesso em 2 mar. 2020.

BRASIL. Decreto n.1, de 11 de janeiro de 1991. Regulamenta o pagamento da compensação financeira instituída pela Lei n. 7.990, de 28 de dezembro de 1989, e dá outras providências. Brasília, DF: 
DOI: $10.12957 /$ teias. $\%$ Y.50574

Presidência da República, 14 jan. 1991. Disponível em http://www.planalto.gov.br/ccivil_03/decreto/1990-1994/D0001.htm. Acesso em 18 jan. 2020. BRASIL. Lei Complementar n.101, de 4 de maio de 2000. Estabelece normas de finanças públicas voltadas para a responsabilidade na gestão fiscal e dá outras providências. Brasília, DF: Presidência da República, 5 mai. 2000.20 Disponível http://www.planalto.gov.br/ccivil 03/leis/lcp/lcp101.htm. Acesso em 18 jan. 2020.

BRASIL. Lei n. 2.004, de 3 de outubro de 1953. Dispõe sobre a Política Nacional do Petróleo e define as atribuições do Conselho Nacional do Petróleo, institui a Sociedade Anônima, e dá outras providências. Revogada pela Lei n. 9.478, de 1997. Brasília, DF: Presidência da República, [1997]. Disponível em http://www.planalto.gov.br/ccivil 03/LEIS/L2004.htm. Acesso em 18 jan. 2020.

BRASIL. Lei n.4.320, de 17 de março de 1964. Estatui Normas Gerais de Direito Financeiro para elaboração e contrôle dos orçamentos e balanços da União, dos Estados, dos Municípios e do Distrito Federal. Brasilia, DF: Presidência da República, 23 mar. 1964. Disponível em http://www.planalto.gov.br/ccivil_03/leis/14320.htm. Acesso em 18 jan. 2020.

BRASIL. Lei n. 7.990, de 28 de dezembro de 1989. Institui, para os Estados, Distrito Federal e Municípios, compensação financeira pelo resultado da exploração de petróleo ou gás natural, de recursos hídricos para fins de geração de energia elétrica, de recursos minerais em seus respectivos territórios, plataformas continental, mar territorial ou zona econômica exclusiva, e dá outras providências. (Art. 21, XIX da CF). Brasília, DF: Presidência da República, 29 dez. 1989. Disponível em http://www.planalto.gov.br/ccivil_03/LEIS/L7990.htm. Acesso em 18 jan. 2020.

BRASIL. Lei n. 9.478, de 6 de agosto de 1997. Dispõe sobre a política energética nacional, as atividades relativas ao monopólio do petróleo, institui o Conselho Nacional de Política Energética e a Agência Nacional do Petróleo e dá outras providências. Brasília, DF: Presidência da República, 1997. Disponível em http://www.planalto.gov.br/ccivil 03/LEIS/L9478.htm. Acesso em 18 jan. 2020.

BRASIL. Lei n. 12.351, de 22 de dezembro de 2010 - Veto. Dispõe sobre a exploração e a produção de petróleo, de gás natural e de outros hidrocarbonetos fluidos, sob o regime de partilha de produção, em áreas do pré-sal e em áreas estratégicas; cria o Fundo Social - FS e dispõe sobre sua estrutura e fontes de recursos; altera dispositivos da Lei no 9.478, de 6 de agosto de 1997; e dá outras providências. Brasília, DF: Câmara dos Deputados, 2010. Disponível em https://www2.camara.leg.br/legin/fed/lei/2010/lei-12351-22-dezembro-2010-609797-veto131111-pl.html. Acesso em 20 jan. 2020.

BRASIL. Lein. 12.734, de 30 de novembro de 2012. Modifica as Leis n. 9.478, de 6 de agosto de 1997, e n. 12.351, de 22 de dezembro de 2010, para determinar novas regras de distribuição entre os entes da Federação dos royalties e da participação especial devidos em função da exploração de petróleo, gás natural e outros hidrocarbonetos fluidos, e para aprimorar o marco regulatório sobre a exploração desses recursos no regime de partilha. Brasilia, DF: Presidência da República, 30 nov. 2012. Disponível em http://www.planalto.gov.br/ccivil 03/Ato20112014/2012/Lei/L12734.htm. Acesso em 18 jan. 2020.

BRASIL. Lei n. 12.858, de 9 de setembro de 2013. Dispõe sobre a destinação para as áreas de educação e saúde de parcela da participação no resultado ou da compensação financeira pela exploração de petróleo e gás natural [...]; e dá outras providências. Brasília, DF: Presidência da República, 2013a. Disponível em http://www.planalto.gov.br/ccivil 03/Ato2011-2014/2013/Lei/L12858.htm. Acesso em 20 jan. 2020. 
DOI: $10.12957 /$ teias. $\%$ Y.50574

BRASIL. Lei 13.005, de 25 de junho de 2014. Aprova o Plano Nacional de Educação - PNE e dá outras providências. Brasília, DF: Presidência da República, 26 jun. 2014. Disponível em http://www.planalto.gov.br/ccivil 03/ ato2011-2014/2014/lei/113005.htm. Acesso em 18 jan. 2020.

BRASIL. Supremo Tribunal Federal (STF). Ação Direta de Inconstitucionalidade n. 4916. Requerente: Governador do Estado do Espírito Santo. Requerido: Presidente da República. Relatora: Min. Cármen Lúcia. Brasília, DF, 2013b. Disponível em http://www.stf.jus.br. Acesso em 19 jan. 2020.

BRASIL. Supremo Tribunal Federal (STF). Ação Direta de Inconstitucionalidade n. 4917. Requerente: Governador do Estado do Rio de Janeiro. Requerido: Presidente da República. Relatora: Min. Cármen Lúcia. Brasília, DF, 2013c. Disponível em http://www.stf.jus.br. Acesso em 19 jan. 2020. BRASIL. Supremo Tribunal Federal (STF). Ação Direta de Inconstitucionalidade n. 4918. Requerente: Assembleia Legislativa do Rio de Janeiro (Alerj). Requerido: Presidente da República. Relatora: Min. Cármen Lúcia. Brasília, DF, 2013d. Disponível em http://www.stf.jus.br. Acesso em 19 jan. 2020.

BRASIL. Supremo Tribunal Federal (STF). Ação Direta de Inconstitucionalidade n. 4920. Requerente: Governador do Estado de São Paulo. Requerido: Presidente da República. Relatora: Min. Cármen Lúcia. Brasília, DF, 2013e. Disponível em http://www.stf.jus.br. Acesso em 19 jan. 2020.

BRASIL. Supremo Tribunal Federal (STF). Ação Direta de Inconstitucionalidade n. 5038. Requerente: Associação Brasileira dos Municípios com Terminais Marítimos, Fluviais e Terrestres de Embarque e Desembarque de Petróleo e Gás Natural - ABRAMT. Requerido: Presidente da República. Relatora: Min. Cármen Lúcia. Brasília, DF, 2013f. Disponível em http://www.stf.jus.br. Acesso em 19 jan. 2020.

BRASIL. Supremo Tribunal Federal (STF). Ação Direta de Inconstitucionalidade n. 6277. Requerente: Governador do Estado do Rio de Janeiro. Requerido: Presidente da República. Relatora: Min. Rosa Weber. Brasília, DF, 2019. Disponível em http://www.stf.jus.br. Acesso em 19 jan. 2020.

CAMPELLO, Marcelo de Moura Carneiro. Atores, interesses e diferentes concepções sobre as reservas do Pré-sal brasileiro: comparando os marcos regulatórios de 2010 e 2016. OIKOS, Rio de Janeiro, v. 17, n. 3, p. 06-30, 2018.

CENTRO BRASILEIRO DE INFRAESTRUTURA (CBIE). Qual a diferença entre regime de concessão e partilha? Disponível em https://cbie.com.br/artigos/diferenca-regime-concessao-partilha/. Acesso em 20 dez. 2019.

GROSTEIN, Marta Dora. Metrópole e expansão urbana: a persistência de processos “insustentáveis”. São Paulo em perspectiva, São Paulo, v. 15, n. 1, p. 13-19, 2001.

INSTITUTO BRASILEIRO DE GEOGRAFIA E ESTATÍSTICA (IBGE). Sintese de indicadores sociais: uma análise das condições de vida da população brasileira: 2018. Rio de Janeiro: IBGE, 2018. INSTITUTO BRASILEIRO DE GEOGRAFIA E ESTATÍSTICA (IBGE). Produto Interno BrutoPIB. Rio de Janeiro: IBGE, 2020. Disponível em https://www.ibge.gov.br/explica/pib.php Acesso em 20 de mar. 2020.

LIMA, Paulo César Ribeiro. Receitas Petroliferas para as áreas de educação e saúde. Consultoria Legislativa da Câmara dos Deputados. Nota Técnica. Brasília-DF, 2013.

MARTINEZ, Paulo Henrique; COLACIOS, Roger Domenech. Pré-Sal: Petróleo e políticas públicas no Brasil (2007-2016). Fronteiras: Journal of Social, Technological and Environmental Science, v. 5, n. 1, p. 145-167, 2016. 
DOI: $10.12957 /$ teias. $\%$ Y.50574

PIRES, Paulo Valois. A evolução do monopólio estatal do petróleo. Rio de Janeiro: Lumen Juris, 2000.

RIO DE JANEIRO (Estado). Secretaria de Estado da Casa Civil e Desenvolvimento Econômico. Atlas da distribuição de royalties do estado do Rio de Janeiro 2018. Rio de Janeiro, 2018a. Disponível em http://www.drm.ri.gov.br/index.php/component/content/article/645-atlas-da-distribuicao-dosrovalties-2018. Acesso em 12 mar. 2020.

RIO DE JANEIRO (Estado). Assembleia Legislativa do Estado do Rio de Janeiro (Alerj). Lei Complementar n. 184 de 27 de dezembro de 2018. Rio de janeiro, 2018b. Dispõe sobre a Região Metropolitana do Rio de Janeiro, sua composição, organização e gestão, define as funções públicas e serviços de interesse comum, cria a autoridade executiva da Região Metropolitana do Rio de Janeiro e dá outras providências. Disponível em http://www3.alerj.ri.gov.br/lotus notes/default.asp?id=2. Acesso em 20 mar. 2020.

RIO DE JANEIRO (Estado). Fundação Centro Estadual de Estatística, Pesquisa e Formação de Servidores Públicos do Rio de Janeiro (CEPERJ). Centro de Estatísticas, Estudos e Pesquisas (CEEP) desenvolve novos mapas incluindo a alteração recente na composição da Região Metropolitana do Rio de Janeiro. Disponível em http://www.fesp.rj.gov.br/Noticias.asp?ident=43. Acesso em 15 jan. 2020.

RIO DE JANEIRO (Estado). Tribunal de Contas do Estado do Rio de Janeiro (TCE-RJ). Contas Municipais 2017. Rio de Janeiro, 2017. Disponível em http://www.tce.ri.gov.br/consultaprocesso/pesquisa?tipo=municipio. Acesso em 20 mar. 2020.

RIO DE JANEIRO (Estado). Tribunal de Contas do Estado do Rio de Janeiro (TCE-RJ). Contas Municipais 2018. Rio de Janeiro, 2018. Disponível em http://www.tce.ri.gov.br/consultaprocesso/pesquisa?tipo=municipio. Acesso em 20 mar. 2020.

SANTOS, Ricardo José dos; AVELLAR, Ana Paula Macedo. Da criação do Conselho Nacional do Petróleo à política de conteúdo local: a trajetória histórica das políticas para a indústria do petróleo e gás natural no Brasil. História Econômica \& História de Empresas, Rio de Janeiro, v. 19, n. 1, p. 221-248, 2016. Disponível em http://www.abphe.org.br/revista/index.php/rabphe/article/view/405. Acesso em 18 jan. 2020.

SILVA, Isabela Morbach Machado. Fundo Social do petróleo: de onde vem e pra onde vai? Revista da Faculdade de Direito-RFD-UERJ, Rio de Janeiro, n. 28, 2015.

SINGER, André. Brasil, junho de 2013: Classes e ideologias cruzadas. Novos estudos CEBRAP, São Paulo, n. 97, 2013.

\section{Informações dos autores}

Fábio Araujo de Souza

Universidade Federal do Rio de Janeiro (UFRJ)

E-mail: f.asouza@yahoo.com.br

ORCID: https://orcid.org/0000-0001-5756-3654

Link Lattes: http://lattes.cnpq.br/7184525100033821 
Janaina Specht da Silva Menezes

Universidade Federal do Estado do Rio de Janeiro (Unirio)

E-mail: janainamenezes@hotmail.com

ORCID: https://orcid.org/0000-0001-5839-7256

Link Lattes: http://lattes.cnpq.br/0470107702074829 